\title{
Influence of wheel rim width on rolling resistance and off-road speed in cross-country mountain biking
}

\author{
Thomas Maier ${ }^{\mathrm{a}}$, Beat Müller, Remo Allemann ${ }^{\mathrm{b}}$, Thomas Steiner ${ }^{\mathrm{a}}$ and Jon Peter Wehrlin ${ }^{\mathrm{a}}$ \\ aSection for Elite Sport, Swiss Federal Institute of Sport, Magglingen, Switzerland; 'bovement and Sport Sciences, Department of Neurosciences \\ and Movement Sciences, University of Fribourg, Fribourg, Switzerland
}

\begin{abstract}
The rim width of cross-country mountain bike wheel sets has increased in recent years, but the effect of this increase on performance remains unknown. The aim of this study was to analyse the influence of rim width on rolling resistance and off-road speed. We compared 3 tubeless wheel sets: $25 \mathrm{~mm}$ inner width as baseline, $30 \mathrm{~mm}$ width with the same tyre stiffness, and $30 \mathrm{~mm}$ width with the same tyre pressure. Three riders conducted 75 rolling resistance tests for each wheel set on a cross-country course. We determined rolling resistance using the virtual elevation method and calculated off-road speeds for flat and uphill conditions using a mathematical model. Baseline rolling resistance $\left(C_{\mathrm{r}}\right)$ was $0.0298,90 \% \mathrm{Cl}[0.0286,0.0310]$, which decreased by $1.4 \%,[0.7,2.2]$ with the wider rim and the same tyre stiffness and increased by $0.9 \%,[0.1,1.6]$ with the wider rim and the same tyre pressure. The corresponding effects on off-road speed were most likely trivial $(0.0 \%$ to $0.7 \%$ faster and $0.1 \%$ to $0.6 \%$ slower, respectively). Because the effect of rim width on off-road speed seems negligible, athletes should choose the rim width that offers the best bike handling and should experiment with low tyre pressures.
\end{abstract}

\author{
KEYWORDS \\ Virtual elevation; cycling; \\ mathematical model
}

\section{Introduction}

Rolling resistance, aerodynamic drag, gravity, and inertia impede the motion of a cyclist (Olds, Norton, \& Craig, 1993). Rolling resistance is particularly crucial in mountain bike crosscountry competitions because of the rough terrain and comparatively low speeds (Bertucci \& Rogier, 2012; Bertucci, Rogier, \& Reiser, 2013; Maier, Müller, Schmid, Steiner, \& Wehrlin, 2018).

The quotient of the force opposing the rolling movement of an object $\left(F_{r}\right)$ divided by the object's normal force defines the coefficient of rolling resistance $\left(C_{\mathrm{r}}\right): C_{\mathrm{r}}=F_{\mathrm{r}} \cdot \mathrm{m}^{-1} \cdot \mathrm{g}^{-1}$ ( $\mathrm{m}$ = total mass, $\mathrm{g}=$ standard gravity; equation for level ground).

Various mechanical properties of a mountain bike wheel influence the wheel's rolling resistance. Maier et al. (2018) have reported differences in $C_{r}$ of up to $15 \%$ between tyres currently used in international competitions, while Macdermid, Fink, and Stannard (2015) have identified the importance of low tyre mass, low tread surface area, low tread depth, and high tyre volume for low $C_{r}$. Bertucci et al. (2013) have also documented the disadvantage of rough tyre tread and the same group has reported how $C_{r}$ depends on the interaction between tyre pressure and ground surface (Bertucci \& Rogier, 2012). Apart from the tyre, the current 29-in. wheels seem to offer lower rolling resistance (by up to $23 \%$ ) than the previous 26 -in. wheels, resulting in a speed increase of 2-3\% (Macdermid, Fink, \& Stannard, 2014; Steiner, Müller, Maier, \& Wehrlin, 2016; Steyn \& Warnich, 2014).
Bike-component manufacturers are currently experimenting with increased rim widths, presumably to improve bike handling. Bike handling describes the control over the bike in technical down- or uphill sections and can therefore influence riding speed or recovery from preceding effort. Segment times or direct measurements of transferred accelerations from impacts can quantify bike handling (Macdermid et al., 2014; Macdermid, Miller, Macdermid, \& Fink, 2015). First developed for fat bikes and plus-size tyres, wider rims have recently been introduced for cross-country bikes as well. A few years ago, cross-country rims had an inner width of around $20 \mathrm{~mm}$, but the models used in competition today range up to $25 \mathrm{~mm}$, with extra-wide rims of up to $30 \mathrm{~mm}$. Because the same tyre mounted on a wider rim spans a larger volume (because of the larger total circumference), it could be speculated that a wider rim will reduce the rolling resistance and therefore would benefit cross-country performance. To date, however, no study has investigated the influence of rim width on off-road rolling resistance; the combined influence on speed is further complicated by the fact that wider rims increase the total mass (additional mass of about $100 \mathrm{~g}$ per wheel set for $30 \mathrm{~mm}$ wide rims compared to $25 \mathrm{~mm}$ ).

The aims of the current study were therefore to quantify the influence of rim width on off-road rolling resistance and to assess the resulting effect on flat and uphill off-road speed.

CONTACT Thomas Maier tomy.maier@gmx.ch S Swiss Federal Institute of Sport, Section for Elite Sport, Hauptstrasse 247, 2532 Magglingen, Switzerland (6) Supplemental data for this article 


\section{Method}

\section{Wheel sets}

We compared 3 wheel sets, each equipped with the same tyre model: the first with an inner rim width of $25 \mathrm{~mm}$ ( $\left.25_{\text {baseline}}\right)$, the second with a width of $30 \mathrm{~mm}$ and the same tyre stiffness $k$ as the baseline set $\left(30_{\text {same } k}\right)$, and the third with a width of $30 \mathrm{~mm}$ and the same tyre pressure $p$ as the baseline set $\left(30_{\text {samep }}\right)$. Baseline tyre pressure for $25_{\text {baseline }}$ and $30_{\text {samep }}$ was $0.275 \mathrm{psi} \cdot \mathrm{kg}^{-1}$ of total system mass (Maier et al., 2018). The vertical tyre stiffness of $30_{\text {samek }}$ against small-obstacle impacts (e.g., roots and rocks) was experimen-

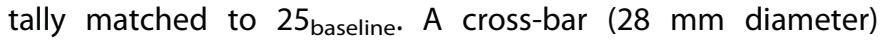
loaded onto the mounted tyre with forces between 50 and $850 \mathrm{~N}$ resulted in the same immersion depth (Silca, 2016). This was achieved with a tyre pressure of $0.255 \mathrm{psi} \cdot \mathrm{kg}^{-1}$ for $30_{\text {samek. }}$ Stiffness is defined as the required force per elastic displacement and is hence associated with puncture protection against sharp-edge impacts.

\section{Study design}

The data collection was carried out on 9 separate days in July and August 2017, during dry and stable weather conditions. A power analysis (power $=80 \%, a=0.05, d=0.33$, paired design) provided the necessary sample size to detect a $C_{r}$ difference of around $1 \%$ ( $1 / 3$ of the measurement error). We conducted $75 C_{r}$ trials, each consisting of $3 C_{r}$ tests (the 3 wheel sets in a randomised order). To control for the possible bias of individual tyre sets, we exchanged them among the wheel sets after trials 25 and 50 . The trials were split between 3 riders (after trial 30 and 43), and each rider conducted 7 separate $C_{d} A$ tests (Figure 1). The institutional review board of the Swiss Federal Institute of Sport Magglingen accepted the study.

\section{Rider characteristics}

The 3 riders were male recreational mountain bikers with anthropometric characteristics similar to elite male mountain bikers (rider 1: age 26 years, height $169 \mathrm{~cm}$, mass $64 \mathrm{~kg}$, effective frontal area $\left(C_{d} A\right) 0.46 \mathrm{~m}^{2}$; rider 2 : age $24,177 \mathrm{~cm}$, $61 \mathrm{~kg}, 0.51 \mathrm{~m}^{2}$; rider 3: age 28, $173 \mathrm{~cm}, 68 \mathrm{~kg}, 0.48 \mathrm{~m}^{2}$ ). They volunteered to participate in the study and gave written informed consent prior to any tests.

\section{Bike setup}

A 29-in.-wheel mountain bike (Scale 900 SL, Scott Sports SA, Givisiez, Switzerland) with front suspension (OPM O.D.L 100 Race, DT Swiss AG, Biel, Switzerland) was used. Wheel sets (XM 1501 Spline One, DT Swiss AG, Biel, Switzerland) differed only in inner rim width (mass of $25 \mathrm{~mm}$ wheel set: $1649 \mathrm{~g}$, mass of $30 \mathrm{~mm}$ wheel set: $1769 \mathrm{~g}$ ) and were equipped with tubeless mounted cross-country tyres (Racing Ralph 2.25 in. TL-easy, Schwalbe, Reichshof, Germany). The outer casing width of this tyre was 54 and $57 \mathrm{~mm}$ and its height above the rim was 48 and $50 \mathrm{~mm}$ (when mounted on the 25 or $30 \mathrm{~mm}$ rim respectively). Power output was measured with a power meter (SRM XX1, SRM, Jülich, Germany) that was dynamically calibrated against first-order principles, as suggested in an earlier study (Maier, Schmid, Müller, Steiner, \& Wehrlin, 2017). Speed was measured with a spoke magnet and sensor (GSC10, Garmin, Olathe KS, USA). Wheel circumference was measured for each rider, wheel set, and tyre set individually by rollouts on a flat surface. Data was recorded on a data logger with a $1 \mathrm{~Hz}$ sampling rate (Edge 510, Garmin, Olathe KS, USA).

\section{$C_{r}$ and $C_{d} A$ test protocol}

For each $C_{r}$ test, the rider rode 5 laps in the seated position without using the brakes (we removed the brake discs) on a

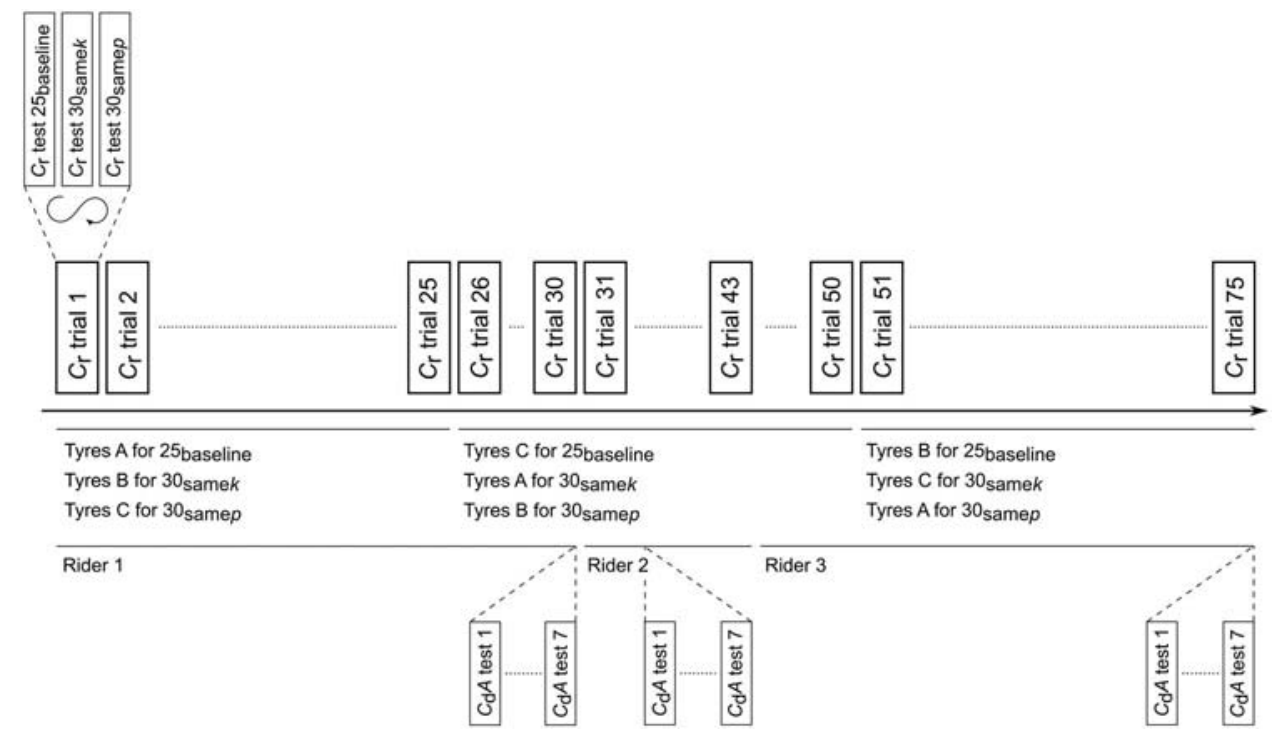

Figure 1. Study design with $75 C_{\mathrm{r}}$ trials, each consisting of $3 C_{\mathrm{r}}$ tests. $C_{\mathrm{r}}$ : coefficient of rolling resistance, $C_{\mathrm{d}} A$ : effective frontal area, $25_{\text {baseline: }} 25$ mm rim width baseline wheel set, $30_{\text {samek }}$ : $30 \mathrm{~mm}$ rim width and baseline tyre stiffness, $30_{\text {samep }}: 30 \mathrm{~mm}$ rim width and baseline tyre pressure. 
small test course with ground-surface conditions typical of a cross-country competition (Figure 2). We specified the exact riding path over roots and rocks with chalk marks. For each $C_{\mathrm{d}} A$ test, the rider rode on a smooth athletic track and accelerated steadily from around $10 \mathrm{~km} \cdot \mathrm{h}^{-1}$ to around $35 \mathrm{~km} \cdot \mathrm{h}^{-1}$ over a period of $5 \mathrm{~min}$.

We registered the following parameters for each test (the respective instrument used is in parentheses): total mass (Model 861, Seca, Hamburg, Germany), air pressure and humidity (Model 622, Testo, Lenzkirch, Germany), tyre pressure (Airmax Pro, Schwalbe, Reichshof, Germany), and power meter 0 -offset. Wind speed and temperature were recorded continuously (SDL350, Extech Instruments, Nashua NH, USA).

\section{Virtual elevation method}

Chung (2012) originally proposed the virtual elevation method to determine $C_{r}$ and $C_{d} A$. Maier et al. (2018) later evaluated the method for off-road use and showed it to be reliable (with a typical error of $2.8 \%$ ) for estimating $C_{r}$ in off-road conditions. Briefly, elevation profiles are calculated from recorded speed and power output data. The correct values can be determined by making iterative adjustments to the unknown $C_{r}$ and $C_{d} A$ while optically verifying the resulting elevation profile. As Maier et al. (2018) have suggested, we estimated both the $C_{r}$ and the $C_{\mathrm{d}} A$ when analysing the $C_{\mathrm{d}} A$ tests and used a fixed $C_{\mathrm{d}} A$ for each rider for the subsequent $C_{r}$ estimations. Three investigators blinded to the wheel set analysed all tests using a cycling performance software (Golden Cheetah 3.1, www.goldenchee tah.org); their estimates were then averaged for further analysis.

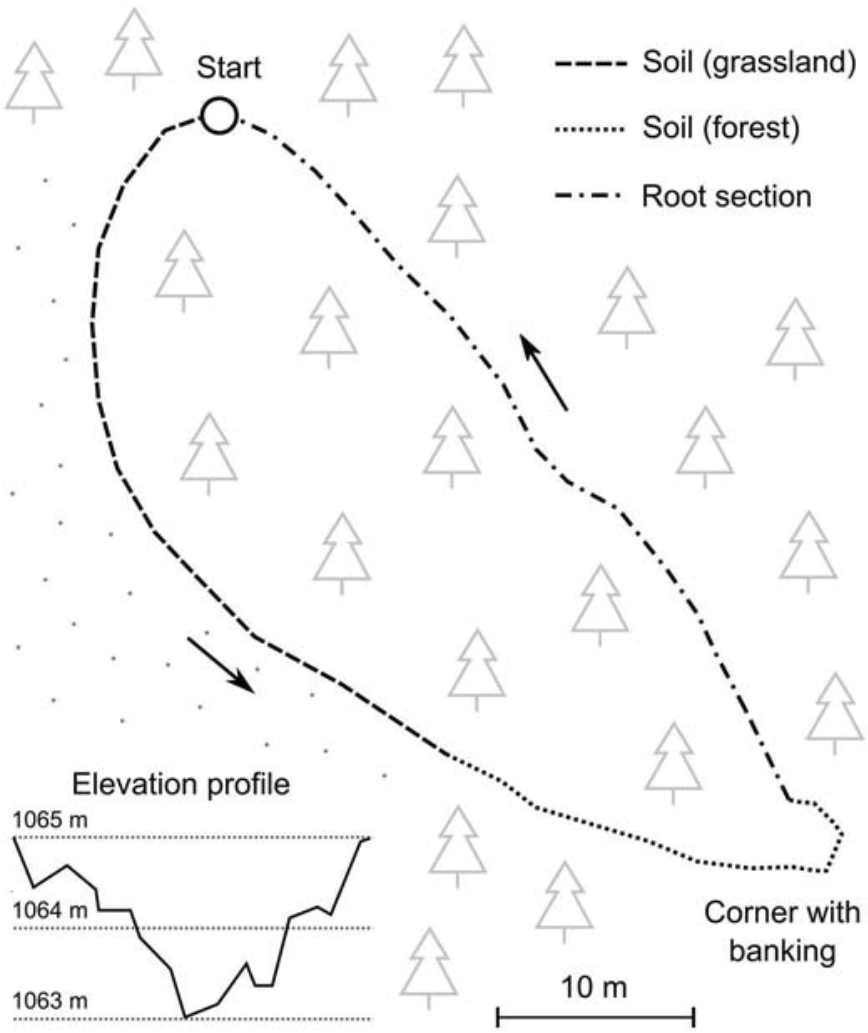

Figure 2. Map of the test course located in Magglingen, Switzerland.

\section{Calculation of off-road speed}

We used the same mathematical model that describes the motion of a cyclist as used in the virtual elevation method ( $P$ = power output, $\eta=$ drivetrain efficiency, $v=$ speed, $s=$ slope, $a=$ acceleration, $\rho=$ air density):

$$
P \eta=C_{r} m g v+s m g v+m a v+0.5 C_{d} A \rho v^{3}
$$

The equation was solved for $v$ (using polyroot() in $\mathrm{R}$ to solve polynomial functions); input parameters were chosen as follows: values for $C_{r}$ and $m$ were chosen for each wheel set based on the statistical analysis (upper and lower $90 \%$ confidence limits). For the $C_{d} A$ we used the mean value over all riders. To account for varying flat and uphill conditions in realistic cross-country competition scenarios, we entered $300 \mathrm{~W}$ and $400 \mathrm{~W}$ for $P$ and $0 \%$ and $10 \%$ for $s ; \rho$ was set to $1.05 \mathrm{~kg} \cdot \mathrm{m}^{-3}$ and $\eta$ to 0.977 for all calculations (Martin, Milliken, Cobb, McFadden, \& Coggan, 1998).

\section{Statistical analysis}

Tests were excluded from the analysis if maximum wind speed exceeded $2 \mathrm{~m} \cdot \mathrm{s}^{-1}(n=12)$. In addition, because a linear model revealed suspicious 0 -offset values compared to ambient temperature (Figure 3), we excluded tests where the 0 offset value deviated by more than $5 \mathrm{~Hz}$ from the expected value $(n=12)$.

We used a statistical programming language ( $R$ 3.3.1, $R$ Core Team, Vienna, Austria) and the Ime4 package (Bates, Mächler, Bolker, \& Walker, 2015) to perform a linear mixed-effects analysis. We analysed the dependence of $C_{r}$ and $m$ from the wheel sets (fixed effect) with random effects (intercept only) for riders, tyre sets, and trials. We observed no obvious deviations from normality or homoscedasticity. The effect sizes of the calculated off-road speeds were assessed using a magnitude-based inference approach (Hopkins, Marshall, Batterham, \& Hanin, 2009) with a smallest worthwhile change in mountain bike performance of 1.2\%, as Paton and Hopkins (2006) have reported.

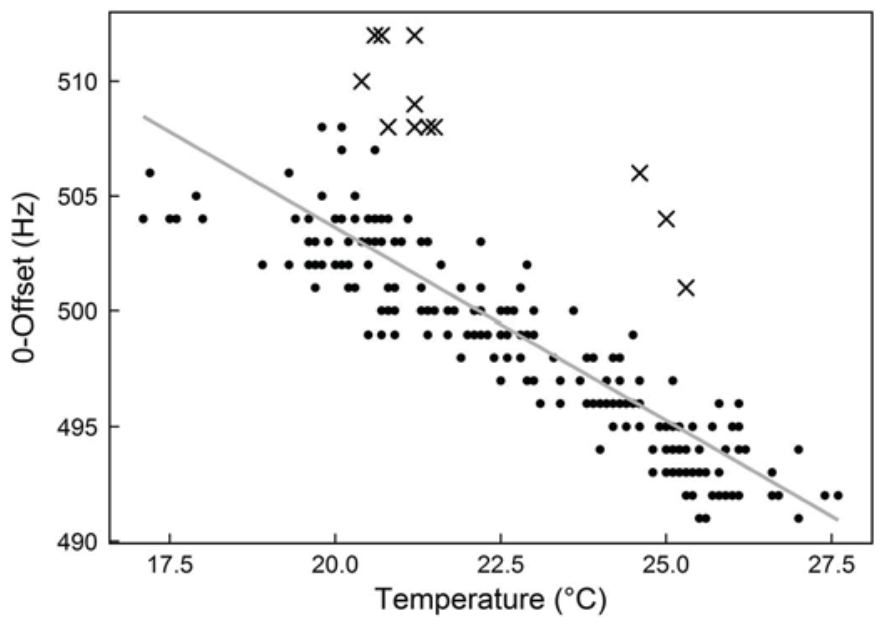

Figure 3. Excluded tests (marked with an X) due to suspicious power meter 0offset values compared with ambient temperature (probably caused by a lightly loaded drive train during zeroing, which would lower measured power output). 
Figures were created with the ggplot2 package (Wickham, 2016); values are presented as mean, $90 \%$ confidence interval (CI) [lower limit, upper limit].

\section{Results}

\section{Rolling resistance}

The $C_{\mathrm{r}}$ for $25_{\text {baseline }}$ was $0.0298,90 \% \mathrm{Cl}[0.0286,0.0310]$. The $C_{\mathrm{r}}$ was $1.4 \%,[0.7,2.2]$ lower for $30_{\text {samek }}(0.0293,[0.0281,0.0305])$, and $0.9 \%,[0.1,1.6]$ higher for $30_{\text {samep }}(0.0300,[0.0288,0.0312])$ compared to $25_{\text {baseline. These effects were consistent across }}$ riders, as the lowest mean $C_{r}$ was always found with $30_{\text {samek }}$ (Figure 4).

$C_{r}$ was negatively correlated with ambient temperature ( $r=-0.95, P<0.001)$ but was not correlated with wind speed $(P=0.43)$. Average riding speed per trial of the 3 riders (rider 1: $12.7 \pm 0.4 \mathrm{~km} \cdot \mathrm{h}^{-1}$, rider 2: $12.2 \pm 0.3 \mathrm{~km} \cdot \mathrm{h}^{-1}$, rider 3: $14.2 \pm 0.8 \mathrm{~km} \cdot \mathrm{h}^{-1}$, mean $\pm \mathrm{SD}$ ) was not correlated with $C_{\mathrm{r}}$ $(P=0.82)$.

The three investigators showed a high level of agreement in their $C_{r}$ estimations (limits of agreement $<0.001, r>0.98$ ). The residual coefficient of variation of the model for the $C_{r}$ values was $2.5 \%,[2.3,2.8]$.

\section{Off-road speed}

The total mass (rider + bike + accessories) with $25_{\text {baseline }}$ was $75.7 \mathrm{~kg}, 90 \% \mathrm{Cl}[72.3,79.1]$. The total mass was $0.10 \mathrm{~kg}$, [0.09, 0.12 ] higher with $30_{\text {samek }}$ and $0.14 \mathrm{~kg},[0.12,0.15]$ higher with $30_{\text {samep }}$ compared to $25_{\text {baseline. }}$ The calculated differences in off-road speed based on these weight differences and the $C_{r}$ differences presented in the preceding section are illustrated in Figure 5 (for different power outputs and slopes). Compared to $25_{\text {baseline, }} 30_{\text {samek }}$ is $0.0 \%$ to $0.7 \%$ faster and $30_{\text {samep }}$ is $0.1 \%$ to $0.6 \%$ slower, depending on power output and slope. All speed differences are below the smallest worthwhile change of $1.2 \%$, however, and correspond to a qualitative descriptor of "most likely trivial".

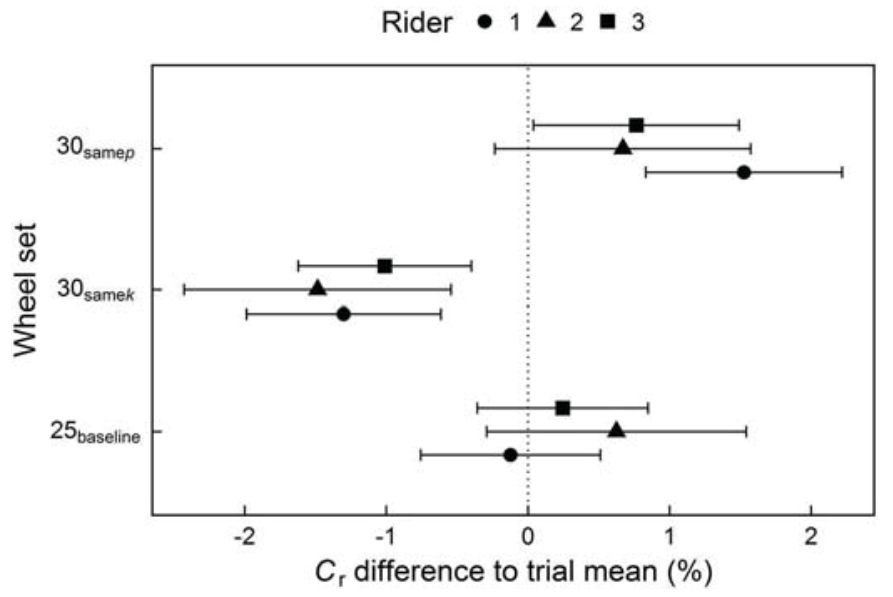

Figure 4. Coefficient of rolling resistance $\left(C_{\mathrm{r}}\right)$ differences between wheel sets. $25_{\text {baseline: }} 25 \mathrm{~mm}$ rim width baseline wheel set, $30_{\text {samek }}: 30 \mathrm{~mm}$ rim width and baseline tyre stiffness, $30_{\text {samep }}: 30 \mathrm{~mm}$ rim width and baseline tyre pressure. Values are illustrated as mean with $90 \%$ confidence interval.

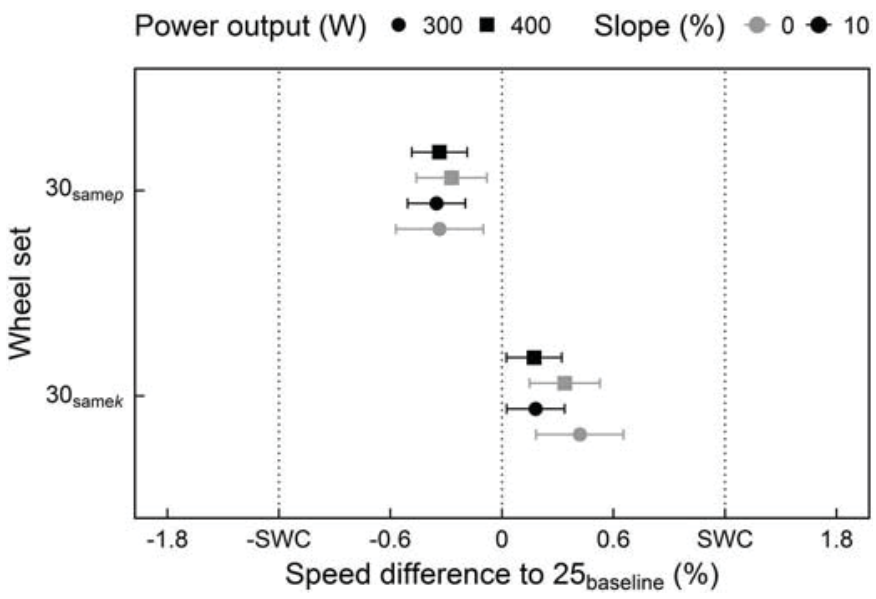

Figure 5. Flat and uphill off-road speed differences between wheel sets. $25_{\text {base- }}$ line: $25 \mathrm{~mm}$ rim width baseline wheel set, $30_{\text {same }}$ : $30 \mathrm{~mm}$ rim width and baseline tyre stiffness, $30_{\text {samep }}: 30 \mathrm{~mm}$ rim width and baseline tyre pressure, SWC: smallest worthwhile change. Values are illustrated as mean with $90 \%$ confidence interval.

\section{Discussion}

The purpose of this study was to analyse the influence of rim width on rolling resistance and off-road speed. Although wider rims with matched tyre stiffness resulted in a minor reduction in rolling resistance, the effect on flat and uphill off-road speed was found to be trivial.

\section{Rolling resistance}

Rolling resistance was slightly reduced with the wider rims, but only when the tyre pressure was reduced to match the tyre stiffness with the setup using the standard rim. This finding indicates that the rolling resistance was not decreased by the increased tyre volume per se but by the concomitant reduction in tyre pressure.

This was the first study to investigate the influence of rim width on off-road rolling resistance, and it did show minor benefits of wider rims. The lower rolling resistance caused by decreased tyre pressure in off-road conditions is in line with Bertucci and Rogier's (2012) results. The present study confirms that a tyre with low pressure can better dampen the impacts of small obstacles on uneven ground surfaces. Macdermid, Miller, et al. (2015) already demonstrated with direct acceleration measurements that wider tyres and low tyre pressure reduce exposure to impacts. However, the influence of rim width on rolling resistance appears to be small compared to the influence of the tyre. Maier et al. (2018) reported differences of up to $15 \%$ between current cross-country tyres and Macdermid, Fink, et al. (2015) reported even higher differences between a larger variety of tyres, whereas the differences due to rim width in the current study were found to amount to only $1-2 \%$.

Nevertheless, the rim widths tested in this study were fairly similar $(25$ and $30 \mathrm{~mm}$ ). The benefits could perhaps be augmented with even wider rims and optimised tyre constructions in the future. One potentially promising area of inquiry would be to investigate technologies that permit lower tyre pressures in order to further reduce rolling resistance while maintaining sufficient puncture protection and bike handling. 


\section{Off-road speed}

The combined influence of small changes in rolling resistance and small increments in mass caused by the wider rims resulted in slightly higher speeds when tyre stiffness was matched and slightly lower speeds when tyre pressure was unaltered. Such small differences correspond to effects in mountain bike cross-country competitions that are most likely trivial, however. Paton and Hopkins (2006) reported a withinathlete variation in performance of $2.4 \%$ and argued that only a difference that surpasses $1.2 \%$ would substantially improve an athlete's medal-winning chances. Even though that study is now over 10 years old (and competitions have become faster and shorter since that time), the conclusion still seems apt, as the differences in the current study did not amount to even half the smallest worthwhile change.

The differences were slightly higher when riding on the flat, because a higher proportion of the power output is used to overcome rolling resistance, as gravity does not hinder the cyclist's forward movement (Bertucci et al., 2013). As we already discussed, other technical modifications seem to offer far greater speed gains. The change from 26-in. to 29-in. wheels and the correct choice of tyre can each augment off-road speed by around 2-3\% (Macdermid et al., 2014; Maier et al., 2018; Steiner et al., 2016; Steyn \& Warnich, 2014). However, it could be speculated that wider rims additionally improve bike handling as Macdermid, Miller, et al. (2015) reported higher speeds with increased tyre size in a short technical descent (two flights of eight steps).

Calculations of off-road speed are valuable for balancing trade-off decisions. Improvements in rolling resistance are often possible by increasing tyre volume at the expense of increasing total mass (e.g., larger wheels, high-volume tyres, and wider rims). Future investigations should thus attempt to find the "sweet spot" where off-road speed is maximised. Athletes should also choose their gear based on their individual morphology and physiology (e.g., body mass and power output) as well as the target competition (e.g., steepness and roughness of the course). A small and light female rider might not always benefit from choosing large wheels and wide rims for a smooth course.

\section{Limitations}

We only used a single tyre model and a tubeless setup in this study; it is unclear if different tyres and setups would interact similarly with different rim widths. We did conduct a large number of tests, however, and using a single tyre model permitted us to change the tyres between wheel sets, thus controlling possible bias of manufacturing variations.

We also only used one wheel-set model. It was difficult to find cross-country wheel sets that only differed in rim width and were available with an inner width of $30 \mathrm{~mm}$. With this approach, any differences were attributable to rim width and were not influenced by the wheel hubs or spokes.

Even though we specified the riding path over roots and rocks, we did not record the exact paths taken by the riders.
Small alterations between paths could potentially bias the $C_{r}$ estimations.

Finally, current cross-country tyres (including those used in this study) are not optimised for $30 \mathrm{~mm}$ wide rims. This may have impaired their performance and mounting stability, leading to safety concerns.

\section{Conclusion}

Because the influence of the tested rim widths ( 25 and $30 \mathrm{~mm}$ ) on flat and uphill off-road speed seems negligible, athletes should choose the rim width that offers the best bike handling. Furthermore, because even small differences in tyre pressure affect rolling resistance, low tyre pressures that offer acceptable puncture protection and bike handling should be considered.

Future studies and component manufacturers should explore the use of even wider rims than are currently in use, combined with optimised tyre constructions, to decrease rolling resistance while preserving bike handling and puncture protection.

\section{Acknowledgments}

We would like to thank Bastien Girod, Marc Gürber, and Fabian Grossmann for their valuable help during the data collection and analysis.

\section{Disclosure statement}

No potential conflict of interest was reported by the authors.

\section{Funding}

This study was supported by the Swiss Federal Institute of Sport Magglingen (SFISM).

\section{References}

Bates, D., Mächler, M., Bolker, B., \& Walker, S. (2015). Fitting linear mixedeffects models using Ime4. Journal of Statistical Software, 67(1), 1-48.

Bertucci, W. M., \& Rogier, S. (2012). Effects of different types of tyres and surfaces on the power output in the mountain bike field conditions: A preliminary study. Computer Methods in Biomechanics and Biomedical Engineering, 15(Suppl. 1), 234-236.

Bertucci, W. M., Rogier, S., \& Reiser, R. F., II. (2013). Evaluation of aerodynamic and rolling resistances in mountain-bike field conditions. Journal of Sports Sciences, 31(14), 1606-1613.

Chung, R. (2012). Estimating CdA with a power meter. Retrieved from anonymous.coward.free.fr/wattage/cda/indirect-cda.pdf

Hopkins, W. G., Marshall, S. W., Batterham, A. M., \& Hanin, J. (2009). Progressive statistics for studies in sports medicine and exercise science. Medicine and Science in Sports and Exercise, 41(1), 3-13.

Macdermid, P. W., Fink, P. W., \& Stannard, S. R. (2014). Transference of 3D accelerations during cross country mountain biking. Journal of Biomechanics, 47(8), 1829-1837.

Macdermid, P. W., Fink, P. W., \& Stannard, S. R. (2015). The influence of tyre characteristics on measures of rolling performance during cross-country mountain biking. Journal of Sports Sciences, 33(3), 277-285.

Macdermid, P. W., Miller, M. C., Macdermid, F. M., \& Fink, P. W. (2015). Tyre volume and pressure effects on impact attenuation during mountain bike riding. Shock and Vibration, (2015, 1-10. 
Maier, T., Müller, B., Schmid, L., Steiner, T., \& Wehrlin, J. P. (2018). Reliability of the virtual elevation method to evaluate rolling resistance of different mountain bike cross-country tyres. Journal of Sports Sciences, 36(2), 156-161.

Maier, T., Schmid, L., Müller, B., Steiner, T., \& Wehrlin, J. P. (2017). Accuracy of cycling power meters against a mathematical model of treadmill cycling. International Journal of Sports Medicine, 38(6), 456-461.

Martin, J. C., Milliken, D. L., Cobb, J. E., McFadden, K. L., \& Coggan, A. R. (1998). Validation of a mathematical model for road cycling power. Journal of Applied Biomechanics, 14, 276-291.

Olds, T. S., Norton, K., \& Craig, N. (1993). Mathematical model of cycling performance. Journal of Applied Physiology, 75(2), 730-737.

Paton, C. D., \& Hopkins, W. G. (2006). Variation in performance of elite cyclists from race to race. European Journal of Sport Science, 6(1), 25-31.
Silca. (2016, June 14). Tire Stiffness [Technical blog]. Retrieved from https://silca. cc/blogs/journal/118616068-part-2-tire-stiffness-wider-is-stiffer-harsher

Steiner, T., Müller, B., Maier, T., \& Wehrlin, J. P. (2016). Performance differences when using 26- and 29-inch-wheel bikes in Swiss National Team cross-country mountain bikers. Journal of Sports Sciences, 34(15), 14381444.

Steyn, W. J., \& Warnich, J. (2014). Comparison of tyre rolling resistance for different mountain bike tyre diameters and surface conditions. South African Journal for Research in Sport, Physical Education and Recreation, 36(2), 179-193.

Wickham, H. (2016). ggplot2: Create elegant data visualisations using the grammar of graphics (Version 2.2.1) [Computer software]. Retrieved from https://cran.r-project.org/web/packages/ggplot2 